\title{
Spontaneous Discharge and Peripherally Evoked Orofacial Responses of Trigemino-Thalamic Tract Neurons during Wakefulness and Sleep
}

\author{
Brian E. Cairns, Shelly A. McErlane, Miguel C. Fragoso, William G. Jia, and Peter J. Soja \\ Division of Pharmacology and Toxicology, Faculty of Pharmaceutical Sciences, The University of British Columbia, \\ Vancouver, British Columbia, Canada V6T $1 Z 3$
}

In the present study, ongoing and evoked activity of antidromically identified trigemino-thalamic tract (TGT) neurons was examined over the sleep-wake cycle in cats. There was no difference in the mean spike discharge rate of TGT neurons when quiet sleep (QS) and active sleep (AS) were compared with wakefulness (W). However, tooth pulp-evoked responses of TGT neurons were decreased during AS when compared to W. Conversely, the responses of TGT neurons to air puff activation of facial hair mechanoreceptors reciprocally increased during AS when compared to $\mathrm{W}$. The present data demonstrate that ascending sensory information emanating from distinct orofa- cial areas is differentially modified during the behavioral state of AS. Specifically, the results obtained suggest that during AS, sensory information arising from hair mechanoreceptors is enhanced, whereas information arising from tooth pulp afferents is suppressed. These data may provide functional evidence for an AS-related gate control mechanism of sensory outflow to higher brain centers.

Key words: behavioral state; brainstem; hair mechanoreceptor; main sensory nucleus; nucleus oralis; sensory; sleep; tooth pulp; trigeminothalamic
The trigemino-thalamic tract (TGT) is a major somatosensory pathway that conveys sensory information from orofacial regions rostrally to the thalamus and on to the cerebral cortex. Both electrophysiological (Sessle and Greenwood, 1976; Sessle and $\mathrm{Hu}$, 1981; Azerad et al., 1982; Sunada et al., 1990; Ro and Capra, 1994) and anatomical labeling (Mizuno, 1970; Woda et al., 1977; Burton and Craig, 1979; Matsushita et al., 1982; Shigenaga et al., 1986; Matthews et al., 1987, 1989) studies performed in acute anesthetized cats have demonstrated that the rostral trigeminal sensory nuclear complex (TSNC) comprising, respectively, the nucleus oralis and the main sensory nucleus, contains a high density of TGT neurons. Recently, we have shown that the tooth pulp-evoked activity of rostral TSNC neurons is suppressed specifically during the behavioral state of active (AS) or REM sleep (Cairns et al., 1995). However, the axonal projection of the recorded cells was not determined.

Given the high density of TGT neurons located in the rostral TSNC in concert with our recent findings of AS-related suppression of these neurons, we hypothesize that synaptic transmission via the TGT is suppressed during the behavioral state of AS. To test this hypothesis, the present study was performed to identify TGT neurons and measure their ongoing and peripherally evoked activity recorded during sleep and wakefulness in chronically instrumented behaving cats. The results obtained via stimuli ap-

Received Aug. 7, 1996; revised Sept. 26, 1996; accepted Sept. 27, 1996.

This work was supported by Grant NS32306 from National Institutes of Health. B.E.C. was supported by a Pharmaceutical Manufacturers Association of Canada/ Medical Research Council of Canada Graduate Studentship.

Correspondence should be addressed to Dr. Peter J. Soja, Faculty of Pharmaceutical Sciences, The University of British Columbia, 2146 East Mall, Vancouver, BC, Canada V6T $1 Z 3$.

Dr. Jia's present address: Departments of Ophthalmology and Surgery, Faculty of Medicine, The University of British Columbia, 2550 Willow Street, Vancouver, BC, Canada V5Z 3N9.

Copyright (C) 1996 Society for Neuroscience $0270-6474 / 96 / 168149-11 \$ 05.00 / 0$ plied to tooth pulp afferents versus facial hair mechanoreceptors suggest that the source of the peripheral input used to activate the recorded neurons is critical in determining the active sleep-related changes that occur in synaptic transmission through the TGT.

A portion of this work has been presented previously (Soja et al., 1996b).

\section{MATERIALS AND METHODS}

Surgical implant procedures. Experiments were conducted in four intact, unanesthetized, chronically instrumented cats that were implanted with a head-restraining device and electrodes for monitoring various states of sleep and wakefulness. In addition, tripolar strut electrodes were chronically implanted in the (contralateral) ventrobasal thalamus (HC: A, 6-8; $\mathrm{L}, 4-6 ; \mathrm{H},-1$ to 2 ) to allow for antidromic activation of rostral TSNC neurons. Further details regarding these surgical implant procedures and those for implanting stimulating electrodes into the canine tooth pulp and inferior alveolar nerve (IAN) may be found elsewhere (Cairns et al., 1995, 1996). All surgical and chronic restraint procedures reported complied with international and institutional regulations.

Cats were allowed to recover fully from each aseptic procedure over a 2 month period, during which time the animal was gradually trained to accept painless head restraint in a chronic stereotaxic frame as described previously (Soja et al., 1993; Cairns et al., 1995). Cats rested quietly under these conditions and readily cycled between naturally occurring states of sleep and wakefulness.

Recording procedures. Behavioral state was constantly monitored by recording electroencephalogram (EEG), electro-oculogram (EOG), ponto-geniculo-occipital (PGO), and electromyogram (EMG) activities. Behavioral state scoring was performed using previously established criteria (Soja et al., 1993, 1995; Cairns et al., 1995, 1996).

The boundaries of the rostral TSNC were demarcated as outlined in detail previously (Cairns et al., 1995). Extracellular spike activity was recorded via tungsten electrodes ( $2 \mathrm{M} \Omega$ ) using an AC-coupled amplifier (bandpass, $0.3-10 \mathrm{kHz}, 1000 \times$, Model 1800, A-M Systems).

Rostral TSNC neurons were identified as TGT neurons if they satisfied the following criteria in response to low-intensity $(0.2 \mathrm{msec}, \leq 500 \mu \mathrm{A})$ thalamic stimuli: (1) constant latency (variability $<0.2 \mathrm{msec}$ ), (2) high frequency following $(\geq 333 \mathrm{~Hz}$ ), and (3) collision with ongoing and/or peripherally evoked action potentials (see Fig. 1) (Price et al., 1976; Lipski, 1981; Ro and Capra, 1994). 


\section{A. Invariant Latency C. Collision-Spontaneous D. Collision - Evoked}

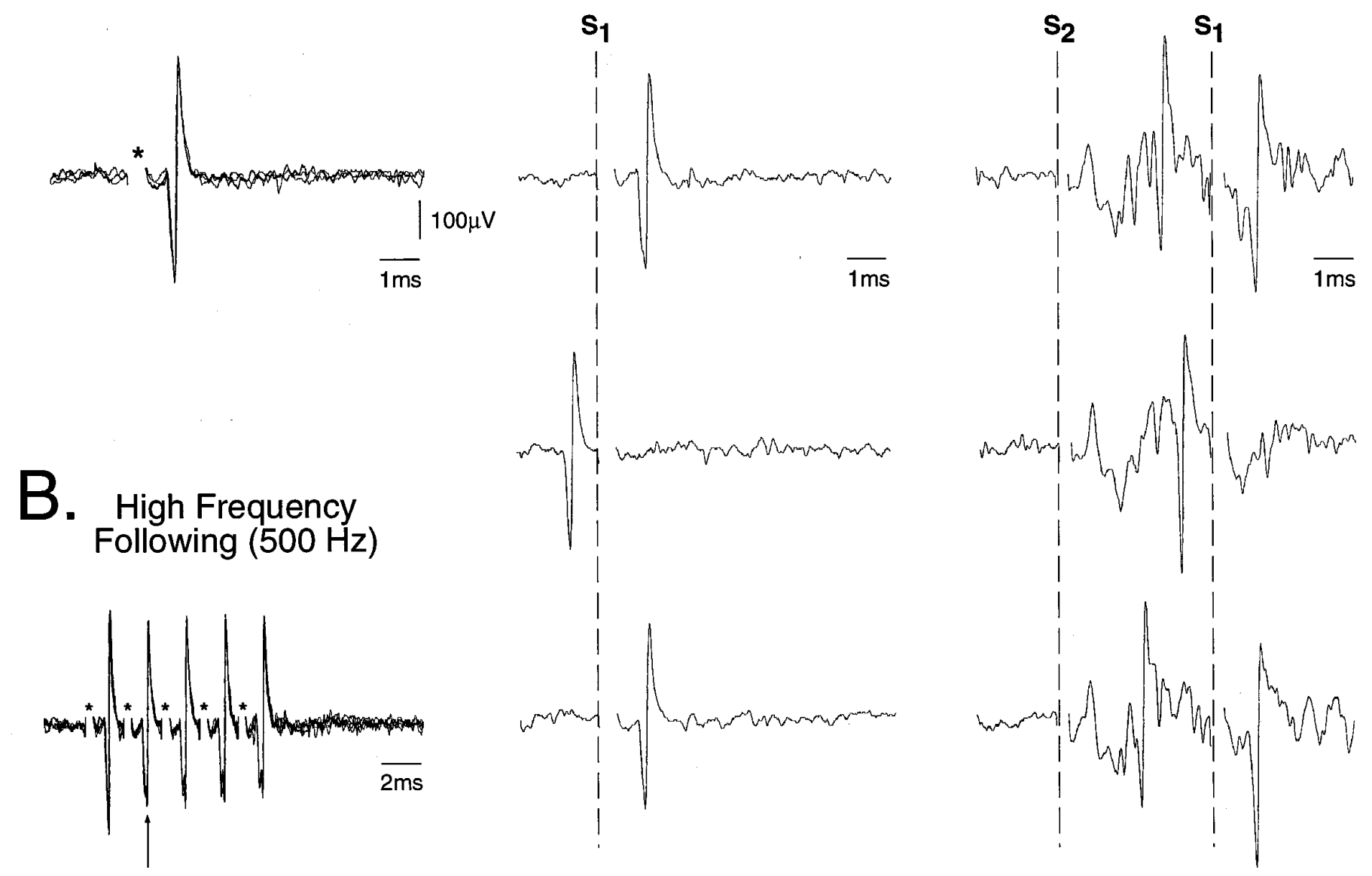

Figure 1. Criteria used to antidromically identify TGT neurons. Five superimposed oscilloscope traces are presented of an antidromic action potential recorded in the rostral trigeminal sensory nuclear complex (TSNC) after stimulation of the thalamus using $(A)$ single pulse $(95 \mu \mathrm{A}, 0.1 \mathrm{msec}, 1 \mathrm{~Hz})$ and $(B)$ a high-frequency $(500 \mathrm{~Hz}, 5$ pulses) train of stimuli. The asterisks in $A$ and $B$ denote the stimulus onset. Consecutive antidromic responses displayed constant latency-to-onset indicating that the action potential resulted from antidromic activation of the axon of the recorded unit. Note that during the high-frequency train in $B$, a progressive increase in the soma-dendritic conduction time is apparent (arrow), indicating that successive antidromic spikes were generated within the relative refractory period for this cell. Both spontaneous $(C)$ and evoked $(D)$ types of collision are presented. In $C$, single oscilloscope sweeps illustrate a collision between the antidromic spike and a spontaneous action potential. The sweeps are aligned by the onset of thalamic stimuli $\left(S_{1}\right)$ as indicated by the dashed vertical line. In $D$, single oscilloscope sweeps illustrate a collision between an orthodromically activated action potential evoked by stimulation of the IAN $\left(S_{2}: 0.2 \mathrm{msec}, 150 \mu \mathrm{A}\right)$ and the antidromic spike. The extracellular field potential evoked by IAN stimulation in $D$ indicates that this neuron was located within the boundaries of the TSNC (Cairns et al., 1995).

Data analysis procedures. The ongoing spike discharge of TGT neurons was measured over $60 \mathrm{sec}$ epochs during each physiologically identified behavioral state (Soja et al., 1996a). From these samples, the mean firing frequency (in $\mathrm{Hz}$ ) was calculated for wakefulness (W), quiet sleep (QS), $\mathrm{AS}$, and recovery from AS. Interspike interval histograms were constructed from these data, and the mean interval and coefficient of variation parameters were calculated for each state.

Peripherally evoked responses of TGT neurons were investigated via electrical stimulation of a mandibular branch of the trigeminal nerve, the IAN $(0.2 \mathrm{msec}, 100-500 \mu \mathrm{A})$ and the canine tooth pulps $(0.2 \mathrm{msec}$, 5-20 $\mu \mathrm{A}$ ), as well as by activation of facial hair mechanoreceptors via innocuous air puffs (FHM; $10-50 \mathrm{msec}$ puff, $0.5 \mathrm{~Hz}$ ). Poststimulus histograms (PSTHs) were constructed from 50 consecutive responses, and the mean activity was calculated and expressed as spikes/stimulus. Behavioral state-related changes in neuronal excitability were assessed for each neuron by comparing the mean activity during wakefulness with that obtained during corresponding periods of QS and AS (see Cairns et al., 1995). Low-intensity electrical stimulation of the canine tooth pulps did not result in aversive behavior or interfere in any way with the normal cycling between episodes of W, QS, and AS (Cairns et al., 1995, 1996).
All data were videotaped, and analyses were performed off-line using computerized data acquisition software (A/DVANCE, Spike 2-1401 plus). A repeated-measures ANOVA followed by a univariate $F$ test, where appropriate, was applied to determine whether significant changes in spontaneous and evoked activity were occurring during different behavioral states. $p$ was set at 0.05 , and all values are reported as mean $\pm \mathrm{SE}$.

Terminal procedures. After completion of all recording sessions and under halothane anesthesia, the ventrobasal thalamus was injected with $1 \mu \mathrm{l}$ of cholera toxin B subunit conjugated with colloidal gold (List Biological, Campbell, CA). Stereotaxic coordinates for injection corresponded to those used for the chronically implanted thalamic stimulating electrode. Approximately $36-48 \mathrm{hr}$ after injection, each cat was killed with pentobarbital and then perfused with saline followed by $4 \%$ paraformaldehyde in phosphate buffer, $\mathrm{pH}$ 7.4. The brainstem and thalamus were removed, and $60 \mu \mathrm{m}$ slices were made with a vibratome slicer. Colloidal gold labeling of TGT neurons was enhanced using a silver-intensifying reagent (InteSEM, Amersham, Buckinghamshire, UK) for $90 \mathrm{~min}$ at $21^{\circ} \mathrm{C}$. All sections were counterstained with neutral red. 

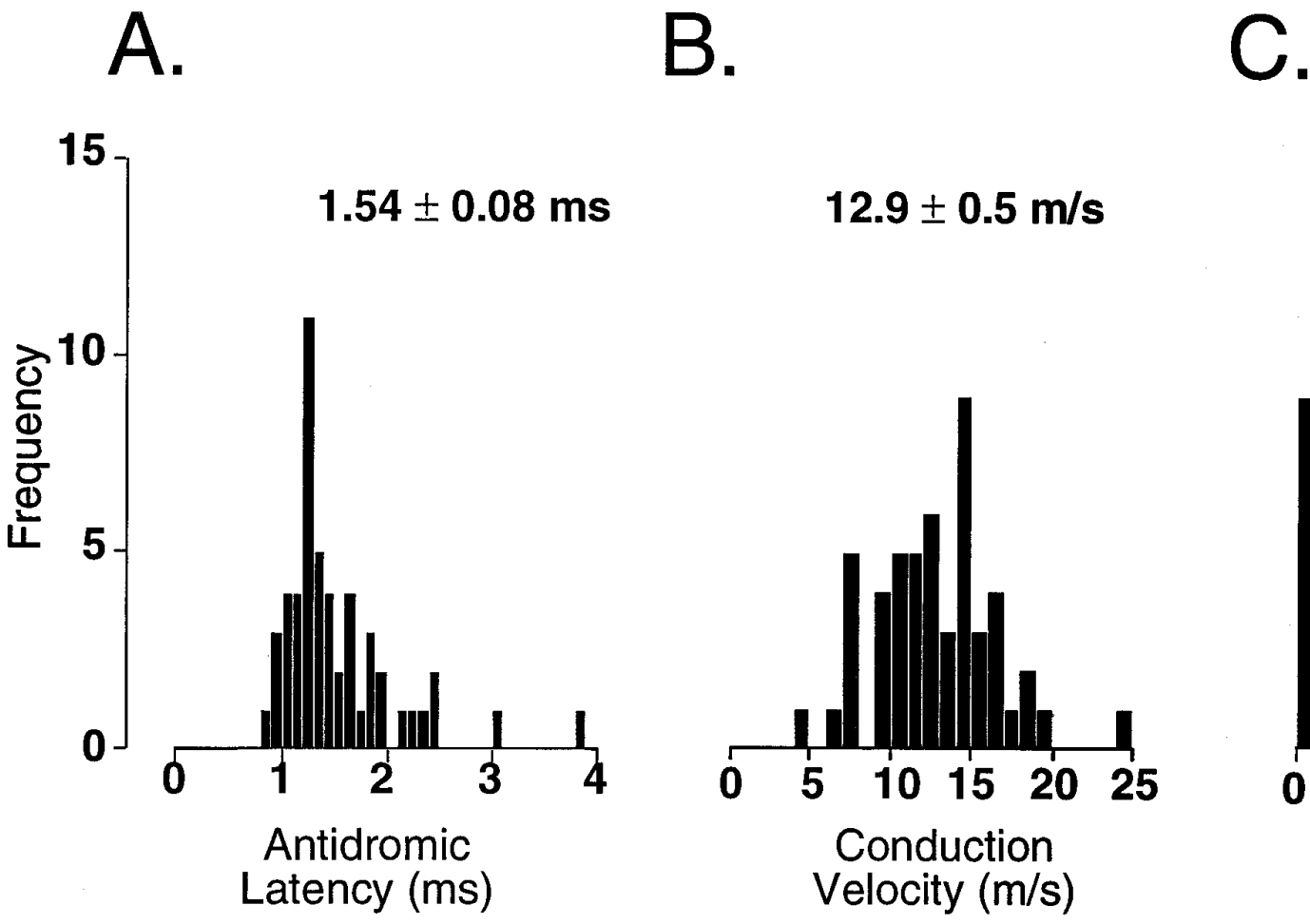

$12.9 \pm 0.5 \mathrm{~m} / \mathrm{s}$

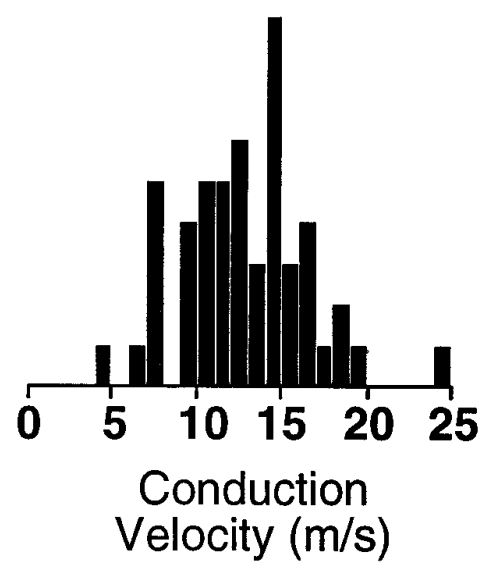

$12 \pm 1 \mathrm{~Hz}$

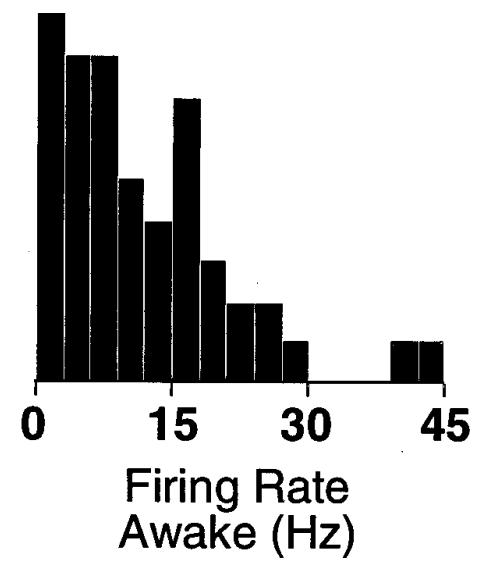

Figure 2. Histograms illustrating the distribution of antidromic latency-to-onset $(A)$, conduction velocity $(B)$, and mean ongoing spike discharge $(C)$ of 51 TGT neurons recorded during the behavioral state of wakefulness. A population mean \pm SE is located above each histogram. Calculated means for antidromic latency-to-onset and conduction velocity do not differ from those reported in anesthetized cats (Sessle and Greenwood, 1976; Ro and Capra, 1994); however, unlike TGT neurons recorded in anesthetized cats (Hu et al., 1981; Ro and Capra, 1994), >90\% of TGT neurons recorded during wakefulness exhibited ongoing spike activity.

\section{RESULTS}

\section{Identification of TGT neurons in the awake cat}

The antidromic latency for all 51 TGT neurons recorded during quiet wakefulness (mean $1.54 \pm 0.08$ msec; Fig. $2 A$ ) is similar to antidromic latencies reported in acute studies (Dubner and Sessle, 1971; Sessle and Greenwood, 1976; Dostrovsky and Hellon, 1978; Hu et al., 1981; Sessle and Hu, 1981; Hyashi et al., 1984; Amano et al., 1986; Sunada et al., 1990; Ro and Capra, 1994).

The conduction distance was estimated by calculating the length of a straight line distance between the stereotaxic coordinates of the thalamic stimulating electrode and the stereotaxic coordinates corresponding to each TGT neuron recorded. Using this technique, the estimated straight line conduction distance from the thalamic stimulating electrodes to TSNC neurons varied from 17.2 to $20.0 \mathrm{~mm}$ (mean $18.0 \pm 0.1 \mathrm{~mm}$ ). Our calculated conduction velocities ranged from 4.5 to 24.4 $\mathrm{m} / \mathrm{sec}$ (mean $12.9 \pm 0.5 \mathrm{~m} / \mathrm{sec}$; Fig. $2 B$ ) and are commensurate with conduction velocities reported for TGT neurons in anesthetized cats (Hu et al., 1981; Hyashi et al., 1984) and the awake monkey (Bushnell et al., 1986).

During quiet wakefulness, the vast majority of TGT neurons $(>90 \%)$ exhibited ongoing spike activity that varied extensively between cells (mean firing rate $12 \pm 1 \mathrm{~Hz}$, range $1-43 \mathrm{~Hz}$; Fig. $2 C$ ). TGT neurons in acute, anesthetized cats exhibit relatively little or no ongoing spike discharge (Hu et al., 1981; Ro and Capra, 1994, 1995).

\section{TGT neuronal responses to peripheral stimuli}

Table 1 summarizes the response characteristics of 27 TGT neurons that were definitively activated by one or more of the pe- ripheral inputs tested during the state of drowsy wakefulness (see Cairns et al., 1995). TGT neurons could be distinguished by their response to peripheral input as follows: (1) neurons that responded exclusively to air puff activation of FHM (37\%), (2) neurons that responded exclusively to electrical stimulation of the IAN (22\%), (3) neurons that responded both to FHM and IAN (15\%), (4) neurons displaying long-latency burst responses to tooth pulp stimulation (15\%), and (5) neurons displaying shortlatency responses to tooth pulp stimulation (11\%; Table 1).

Facial hair mechanoreceptor-activated TGT neurons tended to have shorter mean antidromic latencies than tooth pulp-evoked TGT neurons; however, these differences were not statistically different ( $p>0.05$, Student's $t$ test). The mean firing rate was similar between different categories of TGT neurons, except for the short-latency tooth pulp-evoked neurons, which did not exhibit any ongoing spike activity.

Finally, TGT neurons were identified that responded distinctly when electrical stimuli were applied to the tooth pulps. Four neurons displayed long-latency ( $>15 \mathrm{msec}$ ) bursts of action potentials (4-6 spikes/stimulus), and 3 neurons responded with one or two short-latency ( $<10 \mathrm{msec}$ ) action potentials to tooth pulp stimuli. Spontaneous activity during wakefulness was only observed in the long-latency TGT neurons. All 7 TGT neurons responding to tooth pulp stimuli also responded to stimulation of the IAN. In 2 of the long-latency cells that were tested, air puff stimuli also evoked a response.

To determine whether the long-latency tooth pulp-evoked responses observed were the consequence of reflex jaw movement, the masseter and anterior digastric muscles were stimulated at intensities that resulted in jaw closing or opening, respectively. 
Table 1. Summary of 27 TGT neurons that were distinguished on the basis of their discharge characteristics to various peripheral inputs

\begin{tabular}{|c|c|c|c|c|c|}
\hline & $\begin{array}{l}\text { Facial hair } \\
\text { mechanoreceptor } \\
(\text { FHM })\end{array}$ & $\begin{array}{l}\text { Inferior } \\
\text { alveolar nerve } \\
\text { (IAN) }\end{array}$ & FHM and IAN & $\begin{array}{l}\text { Tooth pulp } \\
\text { long latency }\end{array}$ & $\begin{array}{l}\text { Tooth pulp } \\
\text { short latency }\end{array}$ \\
\hline Number of TGT neurons & 10 & 6 & 4 & 4 & 3 \\
\hline Mean antidromic latency (msec) & $1.3 \pm 0.1$ & $1.6 \pm 0.2$ & $1.2 \pm 0.1$ & $1.9 \pm 0.3$ & $2.1 \pm 0.9$ \\
\hline Mean firing rate $(\mathrm{Hz})$ & $12 \pm 3$ & $10 \pm 2$ & $12 \pm 3$ & $13 \pm 9$ & 0 \\
\hline Mean orthodromic latency from IAN (msec) & NA & $3.6 \pm 0.9$ & $4.0 \pm 1.2$ & $4.2 \pm 0.8$ & $5.7 \pm 2.2$ \\
\hline Mean orthodromic latency from tooth pulp (msec) & NA & NA & NA & $18 \pm 4$ & $7.0 \pm 0.6$ \\
\hline
\end{tabular}

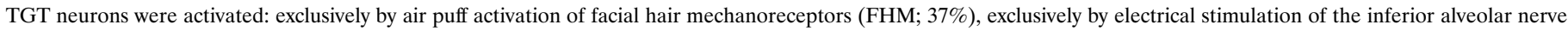

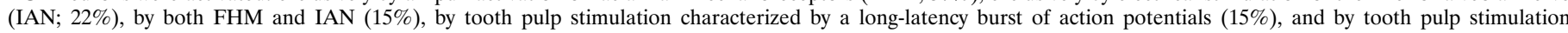

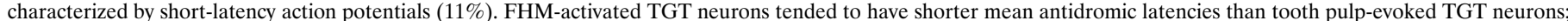

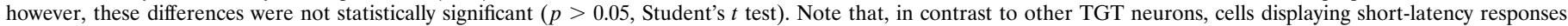

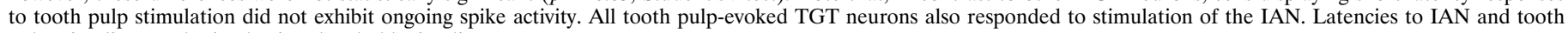
pulp stimuli were obtained using threshold stimuli.

Direct stimulation of either muscle failed to mimic the longlatency tooth pulp-evoked responses in the same cells. In fact, the majority of TGT neurons (44/51) did not respond to tooth pulp stimuli at intensities supramaximal for evoking a jaw opening reflex, suggesting that the observed responses were directly attributable to activation of tooth pulp afferents.

\section{State-dependent changes in the ongoing activity of TGT neurons}

The ongoing spike discharge of 29 of the 51 TGT neurons recorded during quiet $\mathrm{W}$ was also recorded during the behavioral states of QS and AS. Overall, there was no significant difference in ongoing discharge when QS or AS was compared with W ( $p>$ 0.05 , repeated-measures ANOVA). Nevertheless, the histograms of Figure 3 indicate that there was a large range in the mean relative activity, i.e., certain individual neurons were subjected to considerable increases or decreases in spontaneous spike activity during quiet and/or AS. Throughout AS, TGT neurons also displayed paroxysmal bursts of action potentials (Fig. 4). Their paroxysmal spike activity resulted in a $19 \%$ increase in coefficient of variation during AS as compared to wakefulness (mean coefficient of variation $_{\mathrm{W}}, 100 \pm 4 \%$; mean coefficient of variation ${ }_{\mathrm{OS}}$, $114 \pm 5 \%$; mean coefficient of variation ${ }_{\mathrm{AS}}, 119 \pm 6 \%$ ).
To explore whether the sleep-related changes (decreases or increases, Fig. 3) in ongoing firing rate depended on the type of afferent input to these cells, the spike rate for 19 neurons was evaluated on the basis of these cells' response characteristics to peripheral stimuli. Nine cells were found to be activated by FHM afferents and 3 were activated by IAN afferents only, whereas 4 were driven by both types of afferent input. Finally, 3 cells displayed long-latency responses to tooth pulp stimuli. There was no difference in the ongoing spike discharge of any of these categories of TGT neurons when QS or AS was compared to $\mathrm{W}$ ( $p>$ 0.05, repeated-measures ANOVA).

\section{State-dependent changes in peripherally evoked activity of TGT neurons}

In addition to spontaneous activity, the responses of TGT neurons to peripherally applied stimuli were also examined across the sleep-wake cycle. Synchronous inputs arising from periodontal mechanoreceptors, tooth pulp afferents, as well as input from cutaneous afferents innervating the chin and lower lip were tested by applying low-intensity stimuli to the ipsilateral IAN.

IAN evoked responses were obtained for 5 TGT neurons during sleep and wakefulness. When compared with $\mathrm{W}$, the overall group mean magnitude of these evoked responses was not differ-

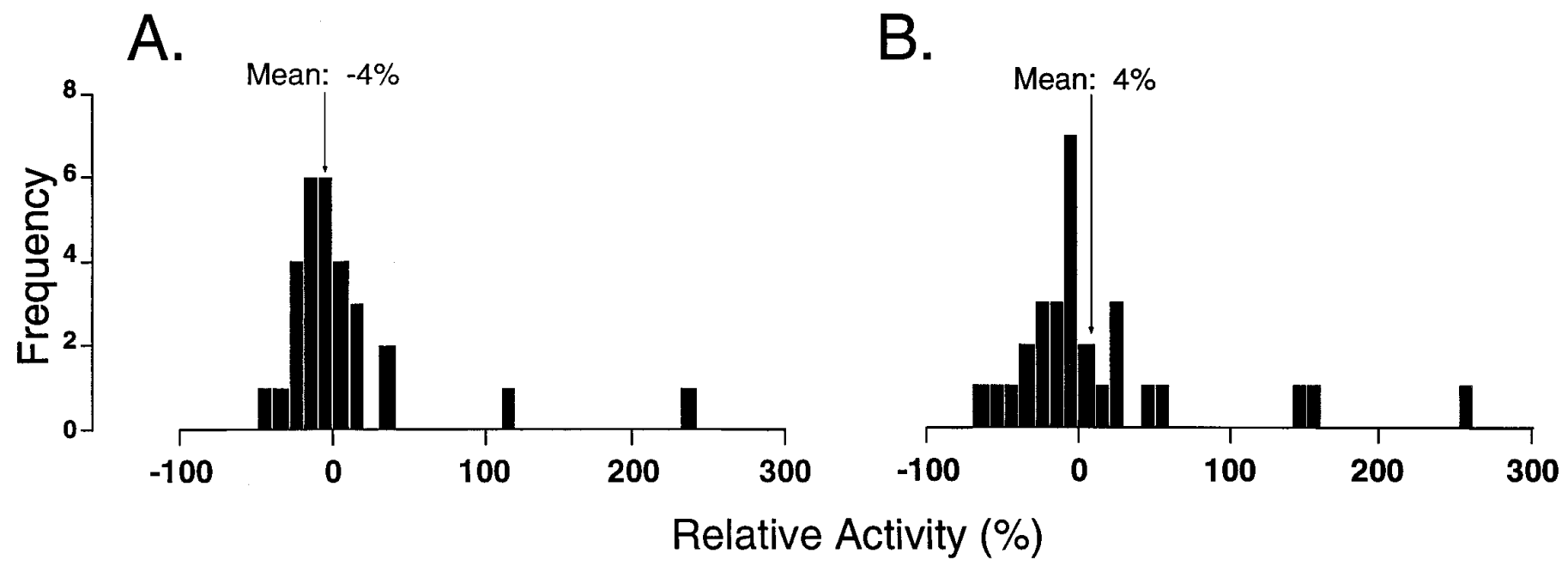

Figure 3. Histograms depicting the distribution of relative change in spontaneous activity of TGT neurons during (QS; $A$ ) and (AS; $B$ ) as compared with wakefulness ( $n=29$ TGT neurons). Relative activity was calculated for each TGT neuron based on the measured firing rate (FR) during sleep and wakefulness, according to the formula $100 \times\left(F R_{\mathrm{W}}-F R_{\mathrm{OS} \text { or } \mathrm{AS}}\right) / F R_{\mathrm{W}}$. Negative values on the abscissa indicate suppression; positive values represent facilitation. For each histogram, there is a normal distribution around zero, indicating that there was no change in ongoing spike discharge of this population of TGT neurons during either QS or AS when compared to W. 


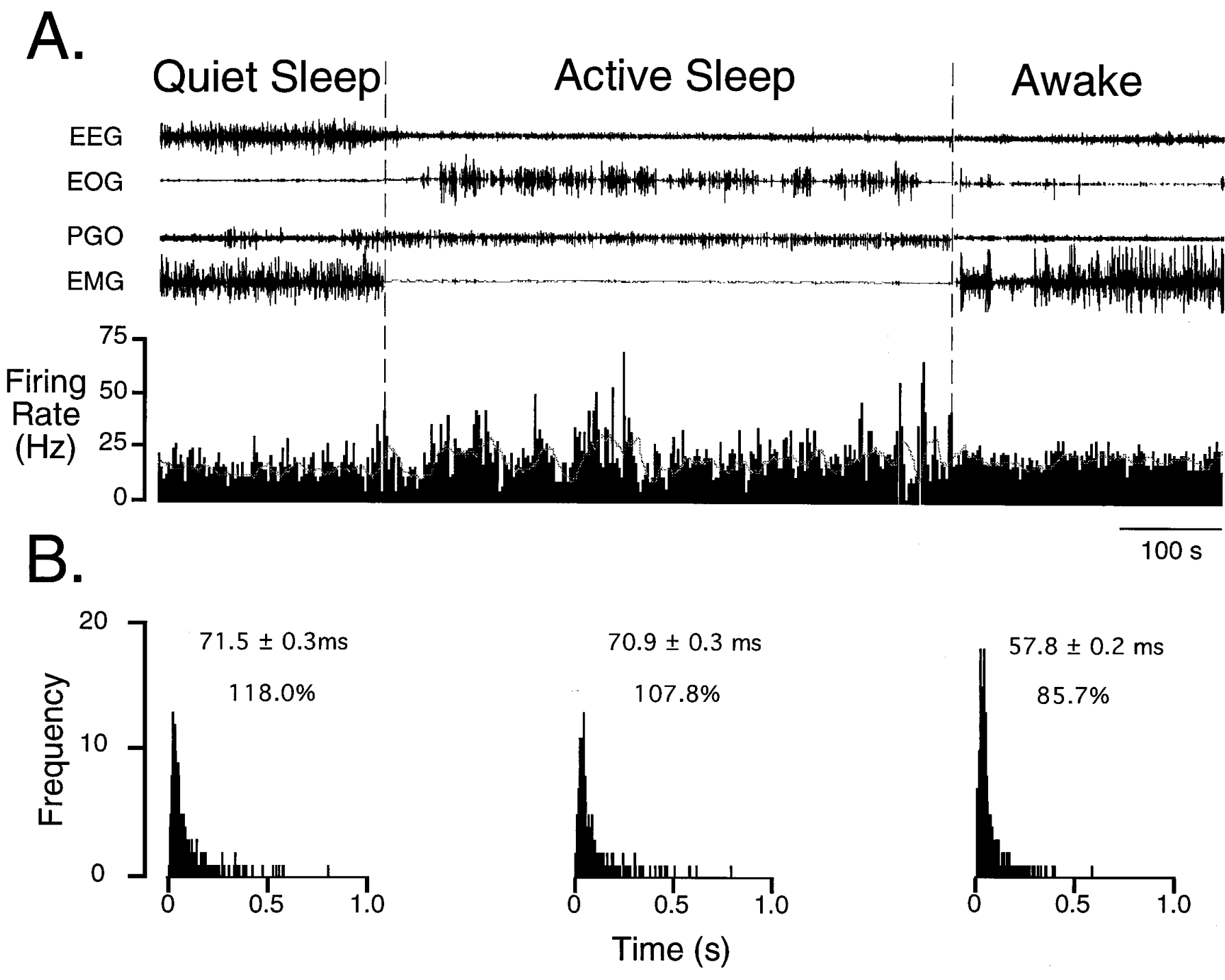

Figure 4. Ongoing spike discharge of a TGT neuron over a sleep/wake cycle. In $A$, the top four traces represent electroencephalogram (EEG), electro-oculogram (EOG), pontine-occipital-geniculate $(P G O)$ wave, and electromyogram $(E M G)$ activities characteristic of the behavioral states indicated above them. The bottom trace represents a rate meter output of ongoing spike discharge (binwidth $1 \mathrm{msec}$ ). The mean firing rate of this cell was $13.9 \mathrm{~Hz}$ during quiet sleep (QS), $14.1 \mathrm{~Hz}$ during active sleep (AS), and $17.3 \mathrm{~Hz}$ during wakefulness (W). Note the occurrence of paroxysmal burst discharges that begins at the onset and continues throughout the state of AS (demarcated by the dashed vertical lines). A sliding average depicted by the dotted hairline (binwidth $15 \mathrm{sec}$ ) is superimposed on the rate meter trace to emphasize further the irregular pattern of spike discharge during AS. In $B$, interspike interval histograms (ISIHs) determined during each state are shown. Compared with W, ISIHs constructed during QS and AS are skewed to the right. This skewing of the ISIH is a result of longer pauses in the firing pattern. Above each ISIH is the mean interval and the coefficient of variation, expressed as a percent. The increased coefficient of variation in quiet and active sleep as compared with wakefulness corroborates the observed paroxysmal burst discharge pattern of spike discharge observed in $A$.

ent during either QS and AS (mean activity $_{\mathrm{W}}, 1.3 \pm 0.3$ spikes/ stimulus; mean activity ${ }_{\mathrm{QS}}, 1.3 \pm 0.3$ spikes/stimulus; mean activity $_{\text {AS }}, 1.3 \pm 0.3$ spikes/stimulus; $p>0.05$, repeated-measures ANOVA). Individually, both increases $(n=3$; range $8-15 \%)$ and decreases $(n=2$, range $22-26 \%)$ in evoked response were observed during AS. An example of an experiment in which the IAN-evoked response in a TGT neurons was modestly suppressed $(26 \%)$ during AS is presented in Figure 5.

The nonuniform results reported above for the IAN might have been caused by the diverse origins of the information conveyed by this nerve. To investigate this possibility, we tested TGT neuronal responses evoked by activation of the ipsilateral canine tooth pulps and hair mechanoreceptors innervating the ipsilateral facial areas surrounding the oral cavity. Tooth pulp-evoked responses were obtained for 6 TGT neurons during sleep and wakefulness. When compared with wakefulness, the overall group mean magnitude of these evoked responses was suppressed by $58 \%$ during AS (mean activity $_{\mathrm{W}}, 2.6 \pm 0.9$ spikes/stimulus; mean activity $_{\mathrm{OS}}$, $2.2 \pm 0.8$ spikes/stimulus; mean activity $_{\mathrm{As}}, 1.1 \pm 0.5$ spikes/ stimulus; $p<0.05$, repeated-measures ANOVA). Figure 6 illustrates an example of AS-related suppression of tooth pulp-evoked activity in a TGT neuron. Note that the magnitude of tooth pulp-evoked activity was decreased during both QS and AS in this TGT neuron. This pattern of suppression was observed in 3 TGT neurons, whereas in the other 3 cells suppression was only observed during AS.

Finally, 8 TGT neurons were driven by air puff stimuli during sleep and wakefulness. When compared with $\mathrm{W}$, the group mean 
Awake
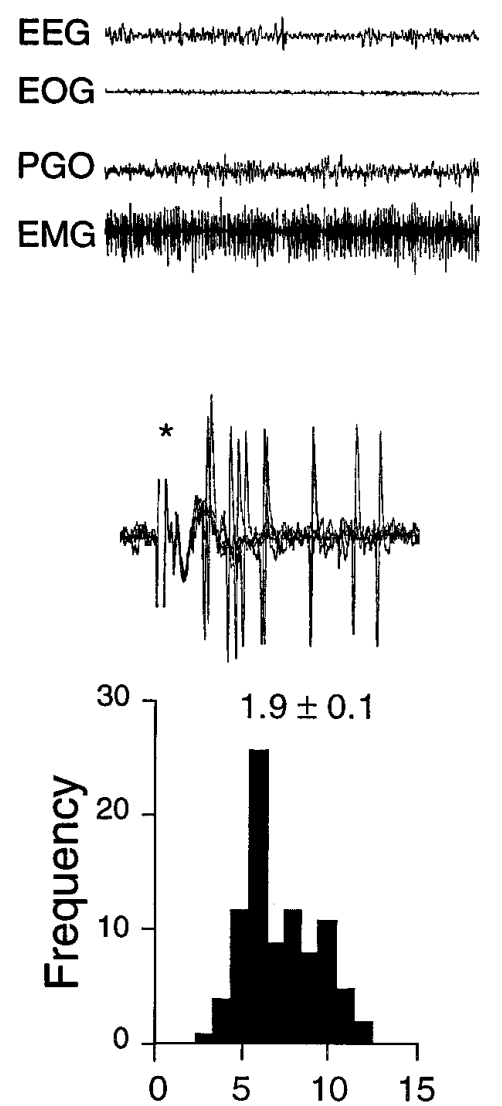

Quiet Sleep

\section{Active Sleep}

Re-awakening
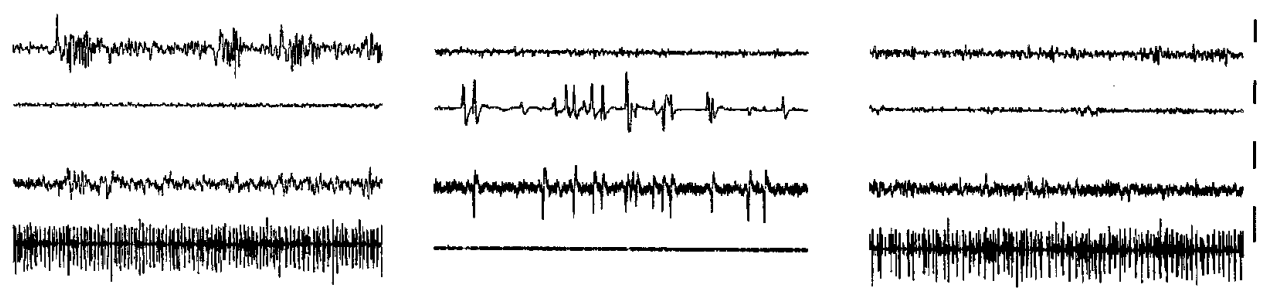

$\overline{1 s}$

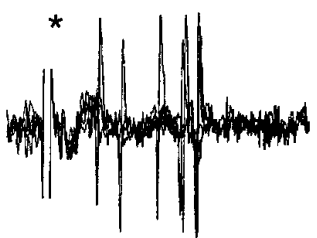

$1.4 \pm 0.1$
$1.6 \pm 0.1$
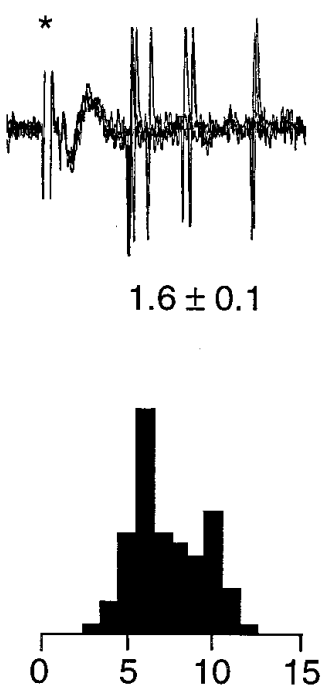

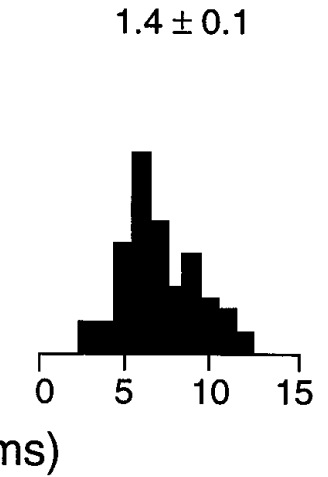

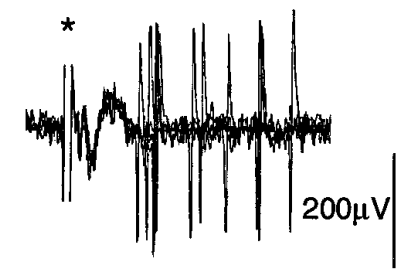

$1.9 \pm 0.1$

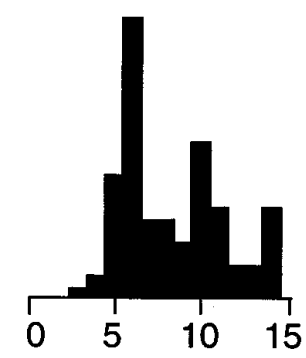

Figure 5. Inferior alveolar nerve (IAN)-evoked activity of a TGT neuron during sleep and waking states. The first four traces represent 10 sec epochs of $E E G, E O G, P G O$, and $E M G$ activity characteristic of wakefulness (W), quiet sleep (QS), and active sleep (AS) and re-awakening (RW). The vertical calibration bars to the right of each trace (EEG, EOG, PGO,EMG) correspond to $50 \mu \mathrm{V}$. Bottom, Five overlaid oscilloscope traces illustrate the spike discharge evoked by low-intensity bipolar electrical stimuli (asterisks) applied to the IAN ( $0.2 \mathrm{msec}, 100 \mu \mathrm{A}, 1 \mathrm{~Hz})$. Poststimulus histograms (PSTH) were constructed from 50 consecutive responses. The number above each histogram indicates the mean evoked activity (in spikes per stimulus \pm SE). Note that in this neuron, IAN-evoked activity decreased by $16 \%$ during QS and $26 \%$ during AS compared with W. In addition, the amplitude of the IAN-evoked extracellular field was also decreased (see Cairns et al., 1995).

magnitude of these evoked responses was unchanged during QS but increased by a mean $38 \%$ during AS (mean activity ${ }_{\mathrm{W}}, 2.1 \pm$ 0.3 spikes/stimulus; mean activity $_{\mathrm{QS}}, 2.3 \pm 0.4$ spikes/stimulus; mean activity $_{\text {AS }}, 2.9 \pm 0.3$ spikes/stimulus; $p<0.05$, repeatedmeasures ANOVA). An example of an AS-related increase in air puff-evoked activity in a TGT neuron is presented in Figure 7. This is a typical example of a robust increase in evoked activity occurring specifically during the state of AS. The results of the above experiments are summarized in Figure 8 and indicate that sensory transmission through the TGT may be controlled during AS in an input-selective manner.

\section{Antidromic firing index of TGT neurons during sleep and wakefulness}

To determine whether a process involving postsynaptic inhibition might be involved in the suppression of tooth pulp-evoked responses, the firing index (FI), a measure of the frequency of antidromic invasion, was calculated during W, QS, and AS (Cairns et al., 1996). This was performed for 2 TGT neurons in which recording conditions were most propitious. One TGT neuron showed an AS-specific decrease in FI that was not dependent on the applied stimulus intensity FI $_{\mathrm{W}}(140 \mu \mathrm{A}), 0.86$; FIQS $(140$ $\mu \mathrm{A}), 0.70$; FIAS $(140 \mu \mathrm{A}), 0.12$; FIAS $(180 \mu \mathrm{A}), 0.10]$. This type of noncompetitive inhibition of antidromic invasion has been attributed to a postsynaptic inhibitory process (Sessle and Dubner, 1970; Dubner and Sessle, 1971; Sessle and Hu, 1981). In the second TGT neuron, there was no change in the FI during sleep when compared with wakefulness [FIW $(36 \mu \mathrm{A}), 0.83$; FIQS (36 $\mu \mathrm{A}), 0.71$; FIAS $(36 \mu \mathrm{A}), 0.92]$. These data suggest that during $\mathrm{AS}$, in addition to presynaptic inhibition via primary afferent depolarization (Cairns et al., 1996), TGT neurons may also be subjected to a postsynaptic form of inhibition.

\section{Anatomical location of labeled TGT neurons}

Search stimuli $(0.2 \mathrm{msec}, 500 \mu \mathrm{A}, 1 \mathrm{~Hz})$ applied to the contralateral ventrobasal thalamus evoked an extracellular field potential when the recording electrode was within the electrophysiologically defined boundaries of the TSNC (Cairns et al., 1995). The amplitude of the thalamic evoked field potential was found to increase in a medial-to-lateral manner as has been described 
Awake
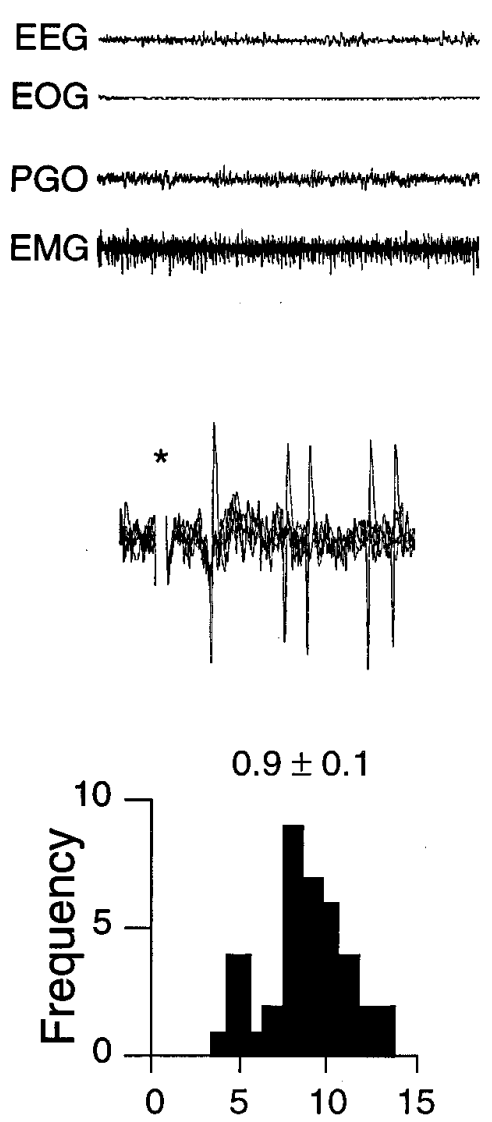

Quiet Sleep
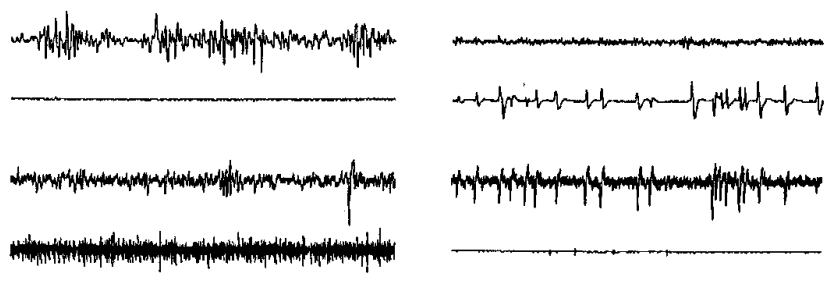

\section{Active Sleep}

Re-awakening
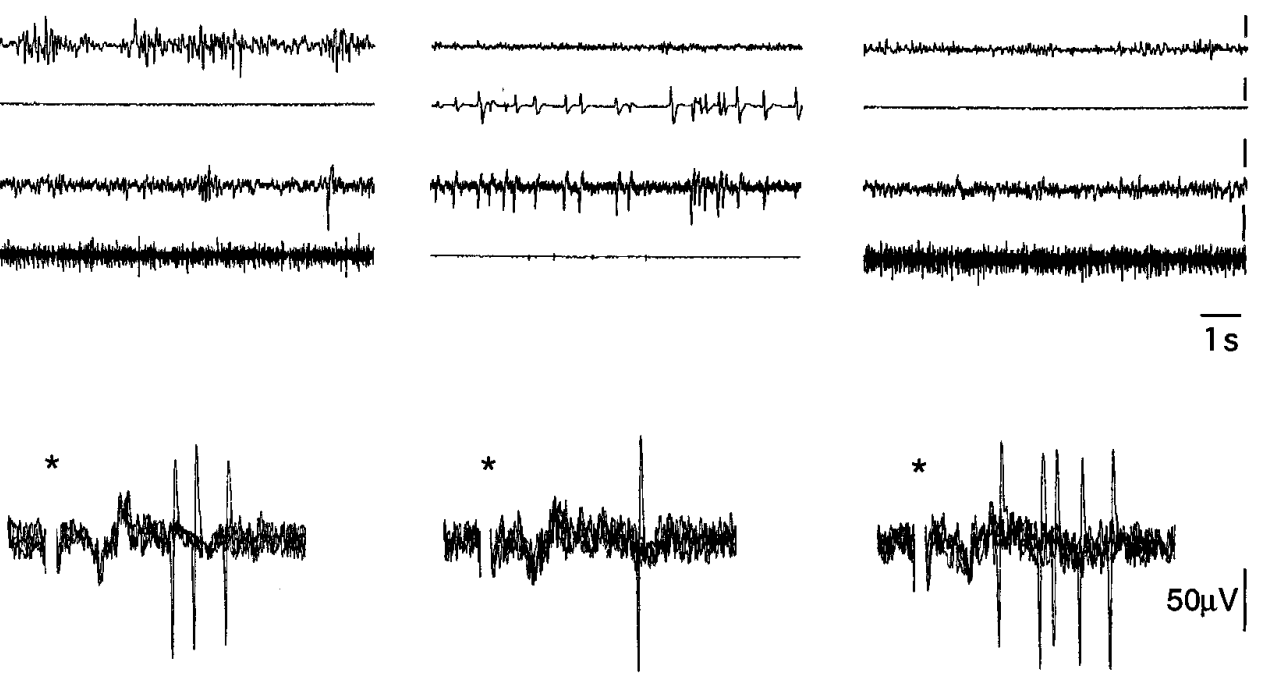

$0.3 \pm 0.1$

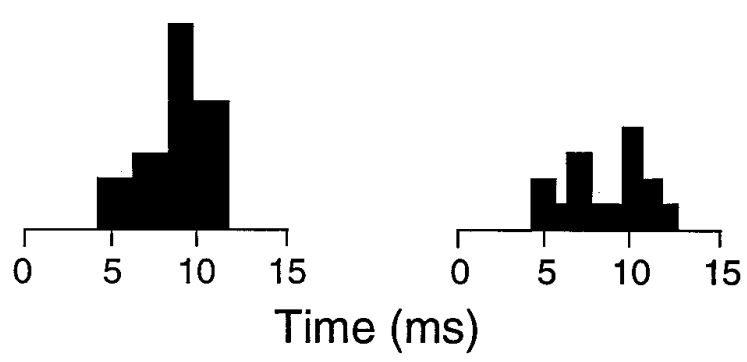
1

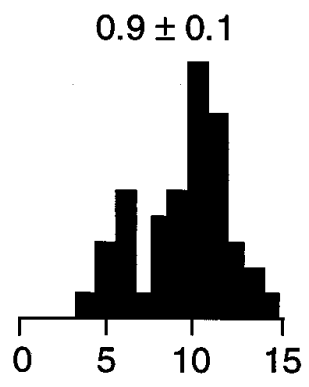

Figure 6. Active sleep-related suppression of tooth pulp-evoked TGT neuronal activity. Oscilloscope traces represent behavioral state and neuronal activity as described in Figure 5. PSTHs were constructed from 50 consecutive responses to low-intensity bipolar electrical stimuli applied to the canine tooth pulps $(0.2 \mathrm{msec}, 12 \mu \mathrm{A}, 1 \mathrm{~Hz})$. The number above each PSTH indicates the mean evoked activity (in spikes per stimulus \pm SE). Note that tooth pulp-evoked activity in this neuron was reversibly suppressed by 33\% during QS and 67\% during AS when compared with W.

previously (Ro and Capra, 1994). All TGT neurons identified in this study were located in the ventrolateral part of the rostral TSNC by our electrophysiological criteria (Cairns et al., 1995) in the vicinity of these thalamic evoked extracellular field potentials. To corroborate our physiological findings further, cholera toxin B subunit conjugated with colloidal gold $(1 \mu \mathrm{l})$ was injected into the contralateral ventrobasal thalamus at stereotaxic coordinates corresponding to those of the chronically implanted thalamic stimulating electrodes. Labeled TGT neurons were located laterally within the caudal main sensory nucleus and nucleus oralis, in agreement with our electrophysiological findings (Fig. 9).

\section{DISCUSSION}

\section{Characteristics of TGT neurons in the awake cat}

The present study was performed to examine the activity of individual TGT neurons in chronic unanesthetized cats during the behavioral states of wakefulness, quiet sleep, and AS. This was accomplished by combining extracellular recording methodologies with classical antidromic techniques to identify TGT neurons in unanesthetized cats. The basic physiological characteristics of these neurons, i.e., antidromic latency and conduction velocity, and their anatomical location substantiate results obtained for TGT neurons in acute anesthetized cats (Mizuno, 1970; Dubner and Sessle, 1971; Sessle and Greenwood, 1976; Dostrovsky and Hellon, 1978; Burton and Craig, 1979; Hu et al., 1981; Sessle and Hu, 1981; Matsushita et al., 1982; Hyashi et al., 1984; Amano et al., 1986; Matthews et al., 1987; Sunada et al., 1990; Ro and Capra, 1994).

The only apparent difference noted in the characteristics of TGT neurons recorded in the awake cat compared with the anesthetized cat preparation is that $90 \%$ of the population of neurons recorded during wakefulness display ongoing spike discharge. In our study, the group mean firing rate for the entire population of active neurons measured $\sim 12$ spikes/sec. In anesthetized cats, TGT neurons exhibit little or no ongoing spike discharge (Dostrovsky and Hellon, 1978; Ro and Capra, 1994). Because TGT neurons recorded in the caudal TSNC of awake monkeys also exhibit ongoing spike activity (Bushnell et al., 1984; Maixner et al., 1989), this difference may be related in part to the anesthetics administered in acute studies. Specifically, the activity of both trigeminal sensory neurons (Boissonade and Matthews, 1993) and L3 dorsal spinocerebellar tract neurons (Fragoso et al., 
Awake
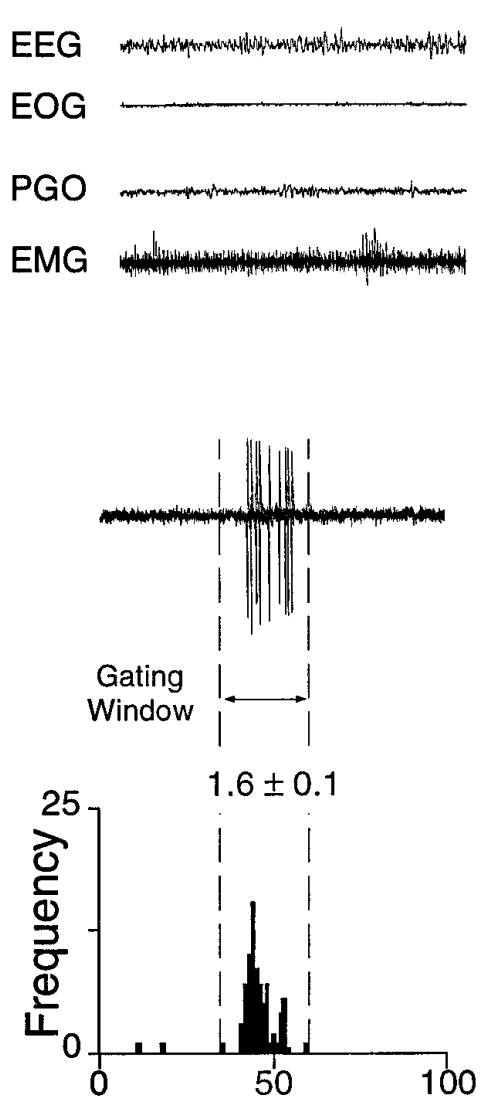

\section{Quiet Sleep}
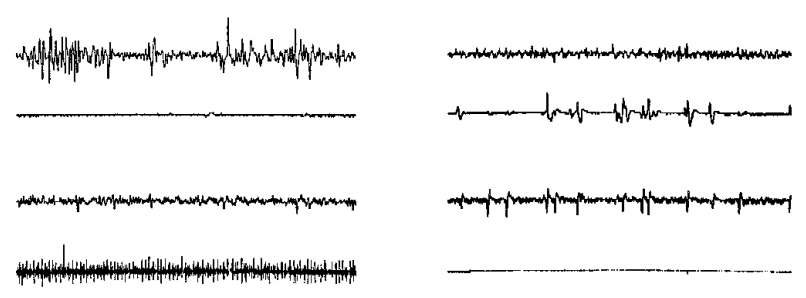

\section{Active Sleep}

\section{Re-awakening}
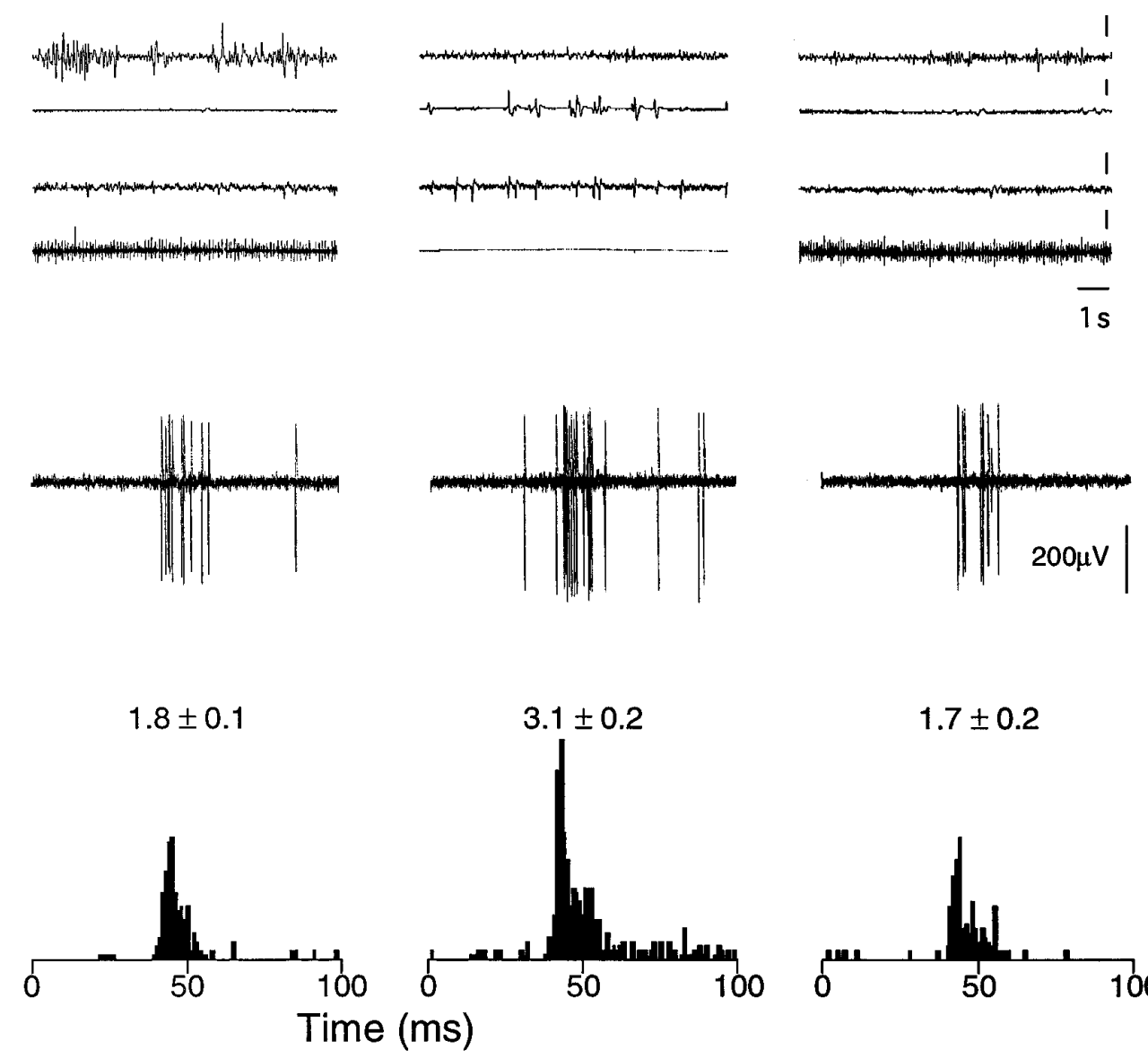

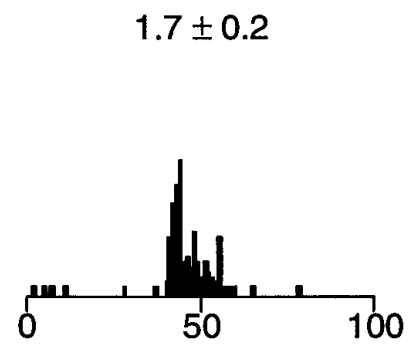

Figure 7. Active sleep-related enhancement of air puff-evoked TGT neuronal activity. Oscilloscope traces represent behavioral state and neuronal activity, respectively, as described in Figure 5. PSTHs were constructed from 50 consecutive responses to a puff of air directed at the ipsilateral face (air puff: $10 \mathrm{msec}, 0.5 \mathrm{psi}, 0.5 \mathrm{~Hz}$ ). The number above each histogram indicates the mean evoked activity (in spikes per air puff \pm SE). Note that the air puff-evoked activity in this cell remained unchanged during QS; however, during AS, activity was increased by $88 \%$ as compared with W.

1995; Soja et al., 1995) are significantly depressed during the state of general anesthesia compared with wakefulness.

It was possible to identify TGT neurons that received peripheral input either from the tooth pulp or from FHMs. Overall, the vast majority of these TGT neurons responded to air puff stimuli activating FHMs. Nevertheless, the proportion of TGT neurons responding to these peripheral inputs in awake cats is consistent with that described for anesthetized cats (Sessle and Greenwood, 1976; Hu et al., 1981; Amano et al., 1986; Sessle et al., 1986; Ro and Capra, 1994). Of particular note was the finding that relatively few TGT neurons received input from tooth pulp afferents (Table 1).

\section{Characteristics of tooth pulp-evoked TGT neurons during wakefulness}

Tooth pulp-evoked TGT neurons recorded during wakefulness comprised two groups based on their response profiles. One group of tooth pulp-evoked TGT neurons responded to tooth pulp stimuli with one or two short-latency action potentials and lacked ongoing spike discharge. The tooth pulp-evoked response characteristics of this group of TGT neurons coincide with "stimulus intensity-independent" TSNC neurons recorded in the awake cat
(Cairns et al., 1995) and TGT neurons recorded in anesthetized cats (Azerad et al., 1982).

The second group of TGT neurons responded to tooth pulp stimuli with longer-latency bursts of action potentials and exhibited ongoing spike discharge during wakefulness. It has been demonstrated that tooth pulp stimuli evoke similar long-latency burst responses in unidentified trigeminal sensory neurons recorded in acute and awake cats (Azerad et al., 1982; Boissonade and Matthews, 1993; Cairns et al., 1995). We suggest that these responses emanate from tooth pulp afferents via a polysynaptic pathway and are not attributable to jaw movement, because no spike discharge was observed when the jaw was opened or closed by digastric or masseter muscle stimulation, respectively.

\section{State-dependent changes in ongoing spike discharge}

Overall, there was no change in the mean spontaneous firing rate of TGT neurons during sleep when compared with wakefulness. During AS, individual neurons did undergo significant changes in mean rate, and both decreases and increases were observed (Figs. $3,4)$. However, TGT neurons displayed paroxysmal bursts of spike activity throughout the state of AS (Fig. 4). Paroxysmal burst activity during AS was confirmed by significant increases in 


\section{A. I. A. N.}

mean:

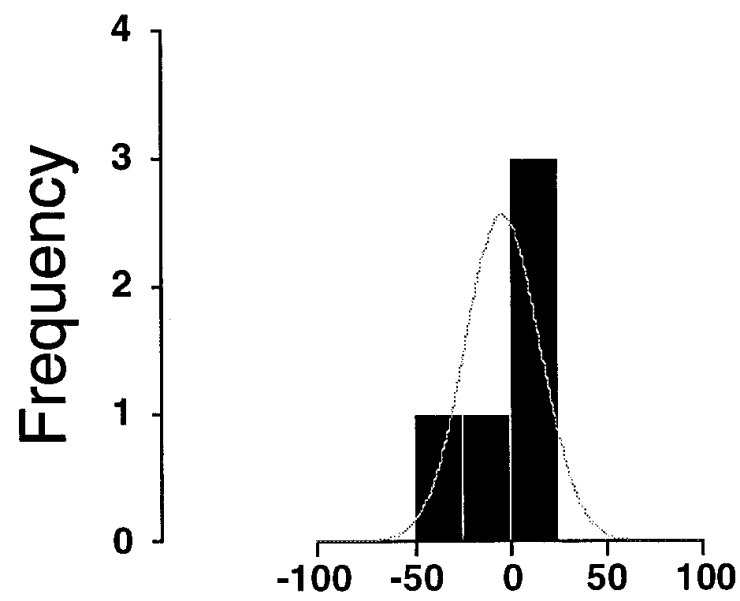

B. Tooth Pulp

$-58 \%$

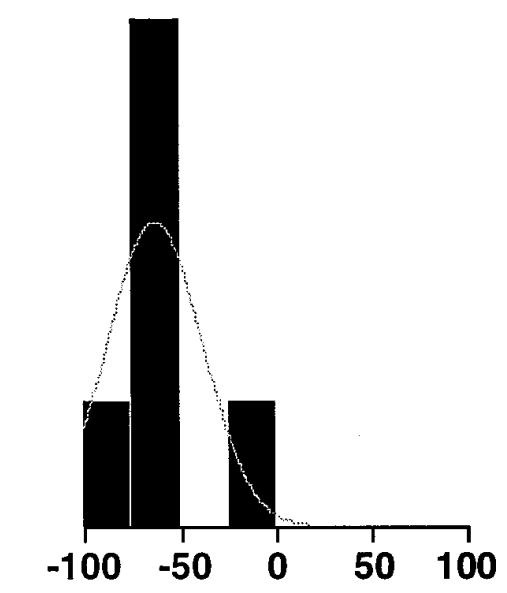

C. Air vurf $38 \%$

\section{Relative Activity (\%)}

Figure 8. Histograms depicting the distribution of relative change in the evoked spike discharge of TGT neurons to different peripheral inputs during active sleep when compared with wakefulness. Negative values on the abscissa indicate suppression; positive values represent facilitation. Note that tooth pulp-evoked responses of TGT neurons were suppressed, whereas the responses to air puff stimuli were enhanced, during active sleep. The curve indicates the distribution of these data around their mean.

the coefficient of variation of interspike intervals for the population of TGT neurons (Cocatre-Zilgien and Delcomyn, 1992; Soja et al., 1996a). The origin and nature of this activity are not presently known. Oneiric twitches of the facial musculature and vibrissae may represent a possible source of afferent input underlying the paroxysmal burst activity of TGT neurons during AS.

These results differ from our previous findings for L3 Clarke's column dorsal spinocerebellar tract (DSCT) neurons (Soja et al., 1996a). The spontaneous firing rate of DSCT neurons as a population decreases during AS relative to $\mathrm{W}$ and QS. This difference may be attributable in part to the different types of afferent information conveyed by TGT (Sessle and Greenwood, 1976; Azerad et al., 1982; Sessle et al., 1986; Ro and Capra, 1994) as opposed to DSCT neurons (Kuno et al., 1973; Mann, 1973; Walmsley, 1991) and/or different central regulatory mechanisms (Cairns et al., 1995, 1996; Soja et al., 1996a).

\section{State-dependent changes in peripherally evoked responses}

The conduction velocity of tooth pulp afferents lies primarily within the A $\delta$ range (Davies et al., 1971; Lisney, 1979; Dostrovsky et al., 1981; Cairns et al., 1996). The present results indicate that the magnitude of TGT neuronal responses to tooth pulp stimulation is suppressed during AS. In contrast, the conduction velocity of cutaneous afferents innervating FHMs lies primarily within the A $\beta$ range (Darian-Smith and Yokota, 1966; Hyashi, 1985). During AS, the magnitude of air puff-driven responses of TGT neurons is markedly increased. These findings indicate that the afferent input to TGT neurons is reciprocally gated throughout the behavioral state of AS.

Although our findings indicate that differential controls are engaged in modifying the responses of TGT neurons during AS, sensory information conveyed via trigemino-thalamic pathways also appears to be modified during changes in attentional focus. In alert monkeys, the magnitude of thermally evoked but not of hair mechanoreceptor-evoked responses is increased when the stimulus becomes the trigger for the performance of a learned task (Bushnell et al., 1984; Maixner et al., 1989; Morrow and Casey, 1992; Tremblay et al., 1993). These findings, together with our current results, indicate that the magnitude of neuronal responses transmitted rostrally to the thalamus depends on the nature of peripheral stimuli and/or the behavioral state.

The present data suggest that an AS-specific gating mechanism may be influencing ascending sensory transmission. The Gate Control Theory introduced by Melzack and Wall (Melzack and Wall, 1965; Wall, 1978) advanced the idea that synaptic transmission between small diameter afferent fibers (A $\delta$ and $\mathrm{C}$ ) and ascending tract neurons was critically dependent on the extent of input from large diameter fibers $(\mathrm{A} \beta)$ and descending drives emanating from higher brain centers. The mechanisms proposed by Melzack and Wall included both presynaptic inhibition via depolarization of $\mathrm{A} \delta$ and $\mathrm{C}$ afferent terminals and postsynaptic inhibition of tract neurons.

We have recently reported that tooth pulp afferent terminals are depolarized supporting a role for presynaptic inhibition during AS (Cairns et al., 1996). In the present study, evidence for postsynaptic inhibition was also demonstrated. Thus, in line with the model proposed by Melzack and Wall, suppressive mechanisms impinging on TGT neurons during AS include both preand postsynaptic forms of inhibition, although it is not yet clear how extensive a role postsynaptic inhibition plays in the suppressive mechanisms influencing TGT neurons during AS.

A central tenet of Melzack and Wall's gate control theory 

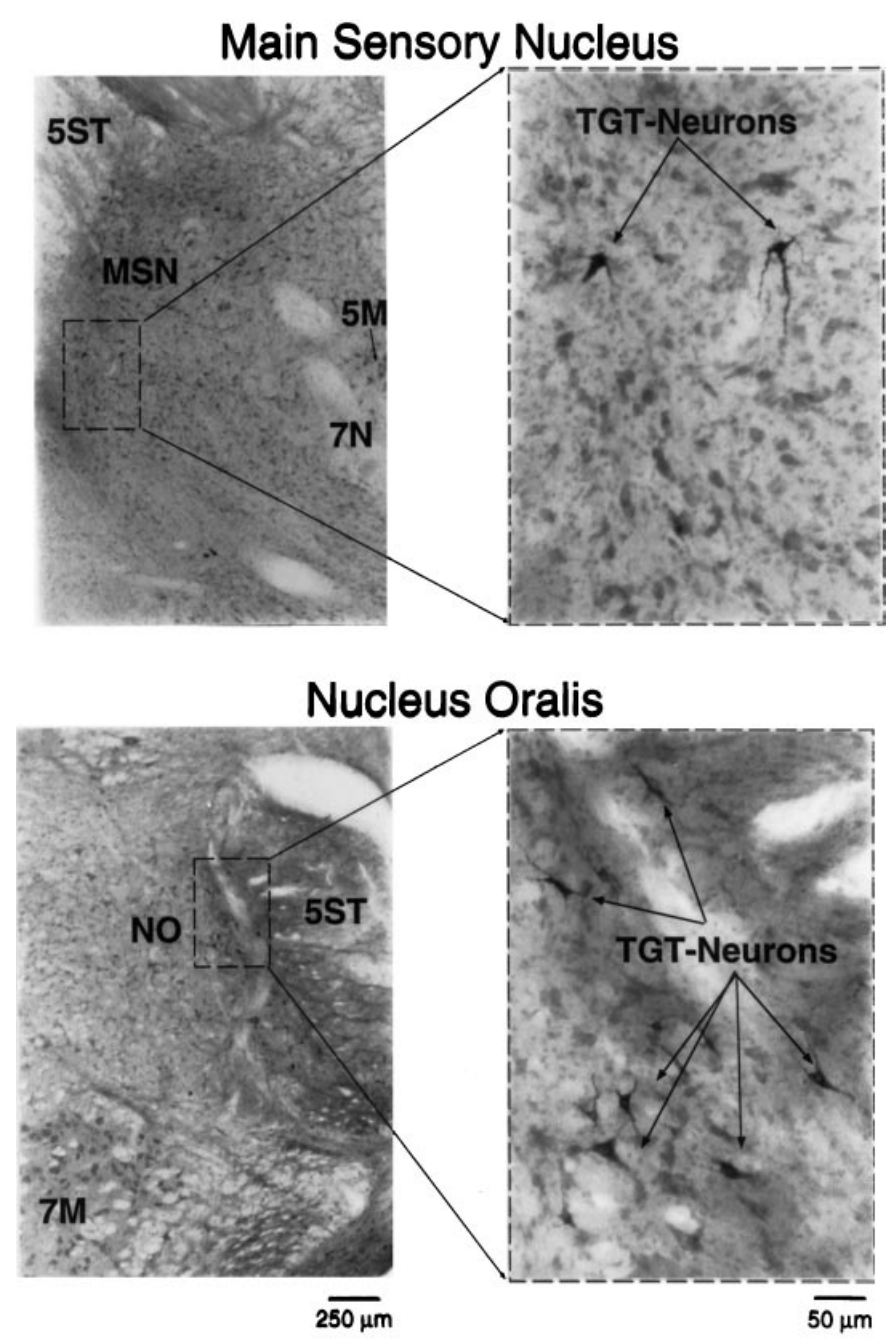

Figure 9. Photomicrographs of TGT neurons located within the rostral TSNC. Stereotaxic coordinates for injection of cholera toxin B subunit conjugated with colloidal gold $(1 \mu \mathrm{l})$ corresponded to those used for the chronically implanted thalamic stimulating electrode. The photomicrographs to the left illustrate the cytoarchitectural features of the main sensory nucleus $(M S N)$ and nucleus oralis $(N O)$. The dashed boxes indicate the area of each photomicrograph that was magnified to the right. These higher-power photomicrographs show examples of labeled TGT neurons in each subnucleus. $5 M$, Trigeminal motor nucleus; $7 N$, facial nerve; $7 M$, facial motor nucleus; $5 S T$, spinal trigeminal tract.

predicts that an increase in afferent input from large-diameter fibers would reduce transmission to projection cells conveyed by small diameter fibers. Because the overall mean spontaneous firing rate of FHM evoked TGT cells did not differ across the sleep-wake cycle, we suggest that an AS-related gating mechanism would be mediated by a descending pathway(s) that may be engaged during AS to exert facilitatory (pre- and/or postsynaptically) and suppressive influences on the pathways from lowthreshold hair mechanoreceptors and tooth pulp afferents, respectively. This facilitation of FHM-evoked TGT neurons might underlie the increase responsiveness of thalamic neurons to FHM stimuli that occurs during AS (Mariotti and Formenti, 1990).

The only other single-unit recording study of "pre-thalamic sensory" neurons during AS was that performed by Kishikawa et al. (1995), who concluded that peripherally evoked "lowthreshold" responses of lumbar "dorsal horn" neurons are increased during REM (active) sleep (Kishikawa et al., 1995).
However, the units recorded by Kishikawa et al. (1995) were not identified antidromically and it is not clear whether their units are indeed segmental interneurons (Jankowska, 1992) or cells comprising a specific ascending sensory tract. To distinguish between these possibilities, more detailed studies need to be performed on identified sensory tract neurons in the spinal cord during sleep and wakefulness (see, for example, Soja et al., 1995, 1996a).

In conclusion, the results of the present study indicate that sensory transmission through the TGT is dependent on behavioral state and source of peripheral input. These findings suggest that during AS, gating of ascending orofacial afferent inputs occurs at the level of second-order tract cells located within the brainstem and may represent an additional site and mechanism whereby tactile and other sensory inputs are modified as a function of behavioral state. Of relevance to our findings are the well established reciprocal interactions between diverse neural pathways (e.g., cholinergic mesopontine vs serotonergic raphe and/or noradrenergic locus coeruleus neurons) underlying behavioral state control (see Hobson and Steriade, 1986; Hobson et al., 1986; Lydic, 1987; Steriade and McCarley, 1990; Williams and Reiner, 1993). Exactly how state-dependent changes in the output of these neural systems are involved in the gating of orofacial input describe herein remains to be determined.

\section{REFERENCES}

Amano N, Hu JW, Sessle BJ (1986) Responses of neurons in feline trigeminal subnucleus caudalis (medullary dorsal horn) to cutaneous, intraoral, and muscle afferent stimuli. J Neurophysiol 55:227-243.

Azerad J, Woda A, Albe-Fessard D (1982) Physiological properties of neurons in different parts of the cat sensory complex. Brain Res 246:7-21.

Boissonade FM, Matthews B (1993) Responses of trigeminal brain stem neurons and the digastric muscle to tooth-pulp stimulation in awake cats. J Neurophysiol 69:174-186.

Burton H, Craig AD (1979) Distribution of trigeminothalamic projection cells in cat and monkey. Brain Res 161:515-521.

Bushnell MD, Duncan GH, Dubner R, He LF (1984) Activity of trigeminothalamic neurons in medullary dorsal horn of awake monkeys trained in a thermal discrimination task. J Neurophysiol 52:170-187.

Cairns BE, Fragoso MC, Soja PJ (1995) Activity of rostral trigeminal sensory neurons in the cat during wakefulness and sleep. J Neurophysiol 73:2486-2498.

Cairns BE, Fragoso MC, Soja PJ (1996) Active sleep-related suppression of feline trigeminal sensory neurons: evidence implicating presynaptic inhibition via a process of primary afferent depolarization. J Neurophysiol 75:1152-1162.

Cocatre-Zilgien JH, Delcomyn F (1992) Identification of bursts in spike trains. J Neurosci Methods 41:19-30.

Darian-Smith I, Yokota T (1966) Cortically evoked depolarization of trigeminal cutaneous afferent fibres in the cat. $\mathrm{J}$ Neurophysiol 29:170-184.

Davies WIR, Scott D, Vesterstrom K, Vyklicky L (1971) Depolarization of the tooth pulp afferent terminals in the brainstem of the cat. J Physiol (Lond) 218:515-532.

Dostrovsky JO, Hellon RF (1978) The representation of facial temperature in the caudal trigeminal nucleus of the cat. J Physiol (Lond) 277:29-47.

Dostrovsky JO, Sessle BJ, Hu JW (1981) Presynaptic excitability changes produced in brain stem endings of tooth pulp afferents by raphe and other central and peripheral influences. Brain Res 218:141-160.

Dubner R, Sessle BJ (1971) Presynaptic excitability changes of primary afferent and corticofugal fibers projecting to trigeminal brain stem nuclei. Exp Neurol 30:223-238.

Fragoso MC, Nixon G, Cairns BE, Soja PJ (1995) Barbiturate-induced suppression of dorsal spinocerebellar tract (DSCT) neurons in the chronic cat. Soc Neurosci Abstr 21:1199.

Hobson JA, Steriade M (1986) Neuronal basis of behavioral state control. In: Handbook of physiology, Sec 1, Vol 4, The nervous system (Mountcastle VB, Bloom FE, eds), pp 701-823. Bethesda, MD: American Physiological Society. 
Hobson JA, Lydic R, Baghdoyan HA (1986) Evolving concepts of sleep cycle generation: from centers to neuronal populations. Behav Brain Sci 9:371-448.

Hu JW, Dostrovsky JO, Sessle BJ (1981) Functional properties of neurons in cat trigeminal subnucleus caudalis (medullary dorsal horn). I. Responses to oral-facial noxious and nonnoxious stimuli and projections to thalamus and subnucleus oralis. J Neurophysiol 45:173-192.

Hyashi H (1985) Morphology of terminations of small and large myelinated trigeminal primary afferent fibers in the cat. J Comp Neurol 240:71-89.

Hyashi H, Sumino R, Sessle BJ (1984) Functional organization of trigeminal subnucleus interpolaris: nociceptive and innocuous afferent inputs, projections to thalamus, cerebellum, and spinal cord, and descending modulation from periaqueductal gray. J Neurophysiol 51:890-905.

Jankowska E (1992) Interneuronal relay in spinal pathways from proprioceptors. Prog Neurobiol 38:335-378.

Kishikawa K, Uchida H, Yamamori Y, Collins JG (1995) Low threshold neuronal activity of spinal dorsal horn neurons increases during REM sleep in cats: comparison with the effects of anesthesia. J Neurophysiol 74:763-769.

Kuno M, Munoz-Martinez DJ, Randic M (1973) Sensory inputs to neurones of Clarke's column from muscle, cutaneous and joint receptors. J Physiol (Lond) 228:327-342.

Lipski J (1981) Antidromic activation of neurones as an analytic tool in the study of the central nervous system. J Neurosci Methods 4:1-32.

Lisney SJW (1979) Evidence for primary afferent depolarization in single tooth-pulp afferents in the cat. J Physiol (Lond) 288:437-447.

Lydic R (1987) State-dependent aspects of regulatory physiology. FASEB J 1:6-15.

Mann MD (1973) Clarke's column and the dorsal spinocerebellar tract: a review. Brain Behav Evol 7:34-83.

Maixner W, Dubner R, Kenshalo Jr DR, Bushnell MC, Oliveras J-L (1989) Responses of monkey medullary dorsal horn neurons during the detection of noxious heat stimuli. J Neurophysiol 62:437-449.

Mariotti M, Formenti A (1990) Somatosensory transmission through the ventroposterolateral thalamic nucleus during sleep and wakefulness. In: The diencephalon and sleep (Mancia M, Marini G, eds), pp 301-312. New York: Raven.

Matthews MA, Hernandez TV, Liles SL (1987) Immunocytochemistry of enkephalin and serotonin distribution in restricted zones of the rostral trigeminal spinal subnuclei: comparison with subnucleus cuadalis. Synapse 1:512-529.

Matthews MA, Hernandez TV, Hoffmann KD, Romanska AK, Liles SL (1989) Synaptic substrates for enkephalinergic and serotoninergic interactions with dental primary afferent terminals in trigeminal subnucleus interpolaris: an immunocytochemical study using peroxidase and colloidal gold. Synapse 4:175-195.

Matsushita M, Ikeda M, Okado N (1982) The cells of origin of the trigeminothalamic, trigeminospinal, and trigeminocerebellar projections in the cat. Neuroscience 7:1439-1452.

Melzack R, Wall PD (1965) Pain mechanisms: a new theory. Science 150:971-978.

Mizuno N (1970) Projection fibers from the main sensory trigeminal nucleus and the supratrigeminal region. J Comp Neurol 139:457-472.

Morrow TJ, Casey KL (1992) State-related modulation of thalamic somatosensory responses in the awake monkey. J Neurophysiol 67:305-317.

Price DD, Dubner R, Hu JW (1976) Trigeminothalamic neurons in nucleus caudalis responsive to tactile, thermal, and nociceptive stimulation of monkey's face. J Neurophysiol 39:936-953.
Ro JY, Capra NF (1994) Receptive field properties of trigeminothalamic neurons in the rostral trigeminal sensory nuclei of cats. Somatosens Mot Res 11:119-130.

Ro JY, Capra NF (1995) Encoding of jaw movements by central trigeminal neurons with cutaneous receptive fields. Brain Res 104:363-375.

Sessle BJ, Dubner R (1970) Presynaptic hyperpolarization of fibers projecting to trigeminal brain stem and thalamic nuclei. Brain Res 22:121-125.

Sessle BJ, Greenwood LF (1976) Inputs to trigeminal brain stem neurons from facial, oral, tooth pulp and pharyngolaryngeal tissues. I. Responses to innocuous and noxious stimuli. Brain Res 117:211-226.

Sessle BJ, Hu JW (1981) Raphe-induced suppression of the jaw-opening reflex and single neurons in trigeminal subnucleus oralis, and influence of naloxone and subnucleus caudalis. Pain 10:19-36.

Sessle BJ, Hu JW, Amano N, Zhong G (1986) Convergence of cutaneous, tooth pulp, visceral, neck and muscle afferents onto nociceptive and non-nociceptive neurones in trigeminal subnucleus cuadalis (medullary dorsal horn) and its implications for referred pain. Pain 27:219-235.

Shigenaga Y, Suemune S, Nishimura M, Nishimuri T, Sato H, Ishidori H, Yoshida A, Tsuru K, Tsuiki Y, Dateoka Y, Nasution ID, Hosoi M (1986) Topographic representation of lower and upper teeth within the trigeminal sensory nuclei of adult cat as demonstrated by the transganglionic transport of horseradish peroxidase. J Comp Neurol 251:299-316.

Soja PJ, Oka J-I, Fragoso M (1993) Synaptic transmission through cat lumbar ascending sensory pathways is suppressed during active sleep. J Neurophysiol 70:1708-1712.

Soja PJ, Fragoso MC, Cairns BE, Oka J-I (1995) Dorsal spinocerebellar tract neuronal activity in the intact chronic cat. J Neurosci Methods 60:227-239.

Soja PJ, Fragoso MC, Cairns BE, Jia W-G (1996a) Dorsal spinocerebellar tract neurons in the chronic cat during wakefulness and sleep: analysis of spontaneous activity. J Neurosci 16:1260-1272.

Soja PJ, Cairns BE, Fragoso MC (1996b) Characteristics of trigeminothalamic tract (TGT) neurons during wakefulness and sleep. In: Abstracts: 8th World Congress on Pain, p 150. Seattle, WA: IASP Press.

Steriade M, McCarley RW (1990) Brainstem control of wakefulness and sleep. New York: Plenum.

Sunada T, Kurasawa I, Hirose Y, Nakamura Y (1990) Intracellular response properties of neurons in the spinal trigeminal nucleus to peripheral and cortical stimulation in the cat. Brain Res 514:189-197.

Tremblay N, Bushnell MC, Duncan GH (1993) Thalamic VPM nucleus in the behaving monkey. II. Response to air-puff stimulation during discrimination and attention tasks. J Neurophysiol 69:753-763.

Wall PD (1978) The gate control theory of pain mechanisms: a reexamination and re-statement. Brain 101:1-18.

Walmsley B (1991) Central synaptic transmission: studies at the connection between primary afferent fibres and dorsal spinocerebellar tract (DSCT) neurones in Clarke's column of the spinal cord. Prog Neurobiol 36:391-423.

Williams JA, Reiner PB (1993) Noradrenaline hyperpolarizes identified mesopontine cholinergic neurons in vitro. J Neurosci 13:3878-3883.

Woda A, Azerad J, Albe-Fessard D (1977) Mapping of the trigeminal sensory complex of the cat: characterization of its neurons by stimulations of peripheral field, dental pulp afferents and thalamic projections. J Physiol (Paris) 73:367-378. 